\title{
Minimally invasive hepatobiliary and pancreatic surgery
}

Citation for published version (APA):

van der Vliet, W. (2021). Minimally invasive hepatobiliary and pancreatic surgery. [Doctoral Thesis, Maastricht University]. ProefschriftMaken. https://doi.org/10.26481/dis.20210924wv

Document status and date:

Published: 01/01/2021

DOI:

10.26481/dis.20210924wv

Document Version:

Publisher's PDF, also known as Version of record

\section{Please check the document version of this publication:}

- A submitted manuscript is the version of the article upon submission and before peer-review. There can be important differences between the submitted version and the official published version of record.

People interested in the research are advised to contact the author for the final version of the publication, or visit the DOI to the publisher's website.

- The final author version and the galley proof are versions of the publication after peer review.

- The final published version features the final layout of the paper including the volume, issue and page numbers.

Link to publication

\footnotetext{
General rights rights.

- You may freely distribute the URL identifying the publication in the public portal. please follow below link for the End User Agreement:

www.umlib.nl/taverne-license

Take down policy

If you believe that this document breaches copyright please contact us at:

repository@maastrichtuniversity.nl

providing details and we will investigate your claim.
}

Copyright and moral rights for the publications made accessible in the public portal are retained by the authors and/or other copyright owners and it is a condition of accessing publications that users recognise and abide by the legal requirements associated with these

- Users may download and print one copy of any publication from the public portal for the purpose of private study or research.

- You may not further distribute the material or use it for any profit-making activity or commercial gain

If the publication is distributed under the terms of Article $25 \mathrm{fa}$ of the Dutch Copyright Act, indicated by the "Taverne" license above, 
Nederlandse samenvatting 



\section{Nederlandse samenvatting}

De laparoscopische chirurgische techniek is ontwikkeld met het doel om het postoperatief herstel na abdominale chirurgie te bespoedigen. Door de klassieke laparotomie te beperken tot een aantal sleutelgat incisies wordt de patiënt minder letsel aangedaan. Dit resulteert in minder postoperatieve pijn en een sneller herstel na de ingreep. De laparoscopische techniek is tegenwoordig de standaard voor een groot aantal abdominale ingrepen waaronder de cholecystectomie en de appendectomie, maar ook voor meer complexe colorectale en bariatrische ingrepen. Met de komst van robot-geassisteerde laparoscopische chirurgie is deze minimaal invasieve techniek verder verfijnd. Dankzij de verbeterde precisie en bewegelijkheid van instrumenten en drie dimensionaal zicht is het mogelijk om steeds meer complexe ingrepen minimaal invasief uit te voeren.

Echter, de overgang van conventionele naar minimaal invasieve chirurgie blijft een uitdaging voor chirurgen en voor centra zonder eerdere ervaring op dat gebied. Met name voor complexe ingrepen waaronder de lever-, alvleesklier- en galwegchirurgie (HPB-chirurgie) is implementatie van de minimaal invasieve benadering een grote uitdaging. Er wordt geschat dat de leercurve voor onervaren teams rond de 40 tot 80 ingrepen omvat. Een dergelijke leercurve voor de implementatie van nieuwe technieken creëert een spanningsveld tussen de potentiele voordelen van innovatie en het beschermen van patiënten tegen vermijdbare complicaties tijdens het opdoen van ervaring. Dit proefschrift beschrijft verschillende klinische studies rond de implementatie van, en leercurves geassocieerd met, innovatie in HPB-chirurgie.

\section{Deel 1: Implementatie en bereiken van bekwaamheid}

Hoofdstuk 2 beschrijft een retrospectieve cohortstudie naar de chirurgische prestaties in een centrum tijdens de transitie van open naar robot-geassisteerde distale pancreatectomie. De kwaliteit van zorg werd gemonitord en vergeleken voor en na de implementatie van het robotprogramma. Het bleek dat dankzij het trainingsprogramma, inclusief virtual reality simulatie, skills lab trainingssessies en de begeleiding van een ervaren coach, de kwaliteit gewaarborgd bleef gedurende de leercurve. Daarnaast bleek dat de robot-geassisteerde distale pancreatectomie in vergelijking met de open operatie resulteerde in minder bloedverlies en een verkorting van de cumulatieve opnameduur met één dag, ten koste van een gemiddelde toename in operatieduur van 70 minuten. Deze resultaten demonstreren de veilige en effectieve implementatie van een minimaal invasieve chirurgische techniek en kunnen potentieel geëxtrapoleerd worden naar andere complexe abdominale ingrepen. 
Een andere strategie om de implementatie van nieuwe chirurgische technieken veiliger en efficiënter te maken is om het opdoen van de eerste ervaring niet plaats te laten vinden in de operatiekamer maar in een gesimuleerde omgeving. In de hedendaagse opleiding van chirurgen vervult 'augmented reality' en simulatie een steeds belangrijkere rol. De luchtvaartindustrie vormt hierbij een voorbeeld, waarbij nieuwe piloten bekwaamheid opdoen in gesimuleerde vluchten en passagiers niet worden blootgesteld aan de gevaren van een leercurve. Idealiter raken chirurgen ook bekwaam met innovatieve technieken in een gesimuleerde omgeving zonder potentiele risico's voor patiënten. De verschuiving van de vroege leercurve, weg van patiënten en naar een gesimuleerde omgeving betekent dat bekwaamheid niet langer gemeten kan worden in termen van morbiditeit of mortaliteit. $\mathrm{Er}$ is hierdoor een behoefte ontstaan aan alternatieve maten voor het meten van bekwaamheid.

De studie beschreven in hoofdstuk 3 onderzoekt de waarde van kijkgedrag en focus in het meten van bekwaamheid bij chirurgen. Twee groepen, één van ervaren en één van onervaren chirurgen werd gevraagd om beelden te bekijken van laparoscopische chirurgie, waarbij kijkgedrag en focus werd gemeten doormiddel van eye-tracking. The resultaten toonden duidelijke verschillen tussen de groepen waarbij ervaren chirurgen sneller contextuele informatie verzamelen (lage fixatie frequentie) en langer focus houden op de regio van interesse (lange duur per fixatie) in vergelijking met onervaren chirurgen. De exacte potentie van eye-tracking in het meten van bekwaamheid en de rol in chirurgische innovatie dient nog verder onderzocht te worden.

\section{Deel 2: Implicaties voor chirurgische teams}

De operatiekamer is een unieke omgeving, waar op hoog tempo door een groot aantal individuen een enorme hoeveelheid aan informatie wordt verzameld, geanalyseerd en verwerkt in activiteiten. Het chirurgische klimaat verandert constant met de introductie van nieuwe technologie in de operatiekamer. De taken en competenties van chirurgische teams moeten met de innovatie mee ontwikkelen om efficiëntie en patiënt veiligheid te blijven waarborgen. In de transitie van conventionele naar minimaal invasieve technieken maken chirurgische teams, net als operateurs, een leercurve door bij het opdoen van die bekwaamheid. Deze teamleercurve is in de huidige literatuur nog onderbelicht.

In de studie in hoofdstuk 4 worden de verschillende manieren om team gedrag en prestaties in de operatiekamer te objectiveren en te scoren met elkaar vergeleken. $\mathrm{Er}$ wordt geconcludeerd dat de huidige literatuur heterogeen en van matige kwaliteit is. De meeste studies gebruikten 'construct-based' beoordelingsinstrumenten, waarbij een aantal vaste domeinen van gedrag, zoals teamwork en back-upgedrag, werden 
gescoord tijdens een operatie. Deze instrumenten geven teams een globale score voor de betreffende domeinen. De scores maken vergelijkingen tussen operaties en teams mogelijk, maar bevatten weinig detail. Daarentegen identificeren 'incident-based' beoordelingsinstrumenten individuele incidenten gedurende de operatie en hun impact op de chirurgische procedure. Wanneer gekeken wordt naar de oorzaken en factoren, die leiden tot het ontstaan van deze incidenten, zorgen deze instrumenten voor waardevolle, concrete data, die het chirurgische klimaat veiliger en efficiënter kunnen maken.

In de studie beschreven in hoofdstuk 5 wordt onderzocht of er verschillen zijn in het aantal en de oorzaak van incidenten gerelateerd aan teamprestaties in open vergeleken met minimaal invasieve HPB-chirurgie. Prestaties werden geobjectiveerd door middel van gestructureerde observaties gedurende 99 ingrepen in de operatiekamers van het Maastricht Universitair Medisch Centrum en het Beth Israel Deaconess Medical Center in Boston. Een minimaal invasieve benadering bleek de sterkste voorspeller te zijn voor een toename in het aantal incidenten. Deze toename werd vooral verklaard door het aantal incidenten gerelateerd aan coördinatie van taken en het omgaan met apparatuur. Uit deze resultaten wordt geconcludeerd dat minimaal invasieve ingrepen meer eisen van chirurgische teams en dat deze teams in mindere maten in staat zijn om efficiëntie en patiëntveiligheid te waarborgen in vergelijking met teams bij open ingrepen. Deze studie impliceert de behoefte aan trainingen voor chirurgische teams, naast de training van chirurgen voorafgaande aan de implementatie van een innovatieve techniek.

\section{Deel 3: Nieuwe toepassingen voor robot geassisteerde laparoscopie}

In hoofdstukken 6 en 7 worden studies gepresenteerd naar nieuwe toepassingen van robot geassisteerde chirurgie in de bovenbuik voor zeldzame indicaties.

Het klieven van het ligamentum arcuatum mediale met of zonder gelijktijdige truncus coeliacus bypass is de meest toegepaste behandeling voor ligamentum arcuatum syndroom. De laparoscopische techniek kent een sneller postoperatief herstel vergeleken met open chirurgie, maar wordt geassocieerd met een hoge conversiekans vanwege ernstige technische complicaties zoals een pneumothorax of arteriële bloeding. In de serie gepresenteerd in hoofdstuk 6 zijn 9 patiënten behandeld middels robot-geassisteerd laparoscopisch klieven van het ligamentum arcuatum en kwamen er geen conversies of complicaties voor. Dankzij de verbeterde precisie en beweeglijkheid van instrumenten en driedimensionaal zicht is de robot geassisteerde techniek voor deze ingreep potentieel superieur aan conventionele laparoscopie. 
In hoofdstuk 7 worden de technieken beschreven voor robot geassisteerde laparoscopische trans-duodenale en duodenum segment resecties. In de serie met 26 patiënten afkomstig uit het Beth Israel Deaconess Medical Center (Boston) en het University of Pittsburg Medical Center (Pittsburg) ondervonden 4 patiënten (15\%) significante complicaties en werd geen van de procedures geconverteerd. Deze studie introduceert en onderbouwt de robot- geassisteerde laparoscopische techniek voor benigne en pre-maligne laesies van het duodenum, die niet in aanmerking komen voor endoscopische resecties, en biedt een alternatief met minder morbiditeit en mortaliteit ten opzichte van de conventionele open techniek. 